\title{
IMPACTOS AMBIENTAIS DOS RESÍDUOS DA SUINOCULTURA INDUSTRIAL E ALTERNATIVAS DE TRATAMENTO
}

Luís Paulo de Lima, Mônica Maria de Almeida Brainer, Waldeliza Fernandes da Cunha, Alexandre Kluge Pereira, Ronaildo Fabino Neto

Instituto Federal Goiano Campus Ceres. E-mail: monica.brainer@ifgoiano.edu.br

\section{RESUMO}

A suinocultura moderna tem se destacado pelo crescimento nas últimas décadas, no entanto, a intensificação do sistema de criação de suínos vem causando grandes problemas ambientais, sendo evidenciada a poluição dos recursos naturais, como ar, solo e água. Em regiões com alta concentração de granjas, grande parte dos dejetos animais é lançada ao solo e em cursos de água sem critérios ou tratamento prévio, transformando-se em importante fonte de poluição ambiental. Quando os dejetos são manejados adequadamente deixam de ser poluentes e passam a ser uma valiosa fonte de fertilizante, além de preservar e melhorar as propriedades física, química e biológica do solo evitando a utilização de insumos derivados do petróleo que são altamente energéticos e caros. Em nosso país são utilizados diversos métodos para o manejo e tratamento dos resíduos, sendo que cada um possui suas particularidades. Este trabalho aborda os impactos ambientais causados pelo descarte irracional dos resíduos da suinocultura industrial e apresenta as técnicas legais de tratamento dos dejetos suínos, visando a sua reutilização com maior valor agronômico.

Palavras-chave: Biofertilizante; Dejetos suínos; Manejo de dejetos; Poluição ambiental; Tratamento de dejetos.

\section{ENVIRONMENTAL IMPACTS OF INDUSTRIAL SWINE RESIDUES AND ALTERNATIVES TREATMENTS}

\begin{abstract}
Modern swine has been notable for growth in the last decades, however, the intensification of pig farming has been causing great environmental problems, evidencing the pollution of natural resources such as air, soil and water. In regions with high concentration of farms, most animal waste is released to the soil and water courses without criteria or prior treatment, becoming an important source of environmental pollution. When waste is properly managed, it is no longer polluting and becomes a valuable source of fertilizer, as well as preserving and improving the physical, chemical and biological properties of the soil, avoiding the use of petroleum-based inputs that are highly energetic and expensive. In our country several methods are used for the handling and treatment of waste, each of which has its own particularities. This paper deals with the environmental impacts caused by the irrational disposal of industrial swine residues and presents the legal techniques of treatment of swine manure, aiming at its reuse with higher agronomic value.
\end{abstract}

Keywords: Biofertilizers; Waste pigs; Waste management; Environment pollution; Waste treatment. 


\section{INTRODUÇÃO}

O Brasil tem apresentado um crescimento moderado na indústria suinícola nas últimas décadas, mantendo uma produção no patamar da competitividade internacional, sendo o único país da América do Sul entre os dez maiores produtores de carne suína apresentando uma posição crescente e ganhando posições ano após ano (FERREIRA, 2012). No entanto, a atividade da suinocultura, pelo seu crescimento, vem causando grandes problemas ambientais, sendo evidenciada a poluição dos recursos naturais, como ar, solo e água.

De acordo com Dartora et al. (1998) em regiões com alta concentração de suínos, grande parte dos dejetos é lançada ao solo sem critérios e em cursos de água sem tratamento prévio, transformando-se em importante fonte de poluição ambiental. Além disso, por não receberem tratamento adequado, também contribuem para o aumento da produção de insetos nocivos, como por exemplo, o borrachudo (Simulium pertinax). Isso significa mais de 192 milhões de $\mathrm{m}^{3}$ /ano de água demandada pelo setor de produção, com um potencial poluente da ordem de 2,5 milhões de toneladas de Demanda Bioquímica de Oxigênio $\left(\mathrm{DBO}_{5}\right)$, concentrados basicamente na região Sul (38\%) (PERDOMO, 2001).

A evolução da produção evidencia problemas na adequação e no licenciamento ambiental das propriedades, podendo causar poluição caso não se utilizem sistemas de tratamento dos resíduos. Como a atividade da suinocultura produz considerável quantidade de matéria orgânica, representada, principalmente, pelos dejetos dos animais, há necessidade de utilização de tecnologias que possam minimizar os danos causados ao meio ambiente.

Os dejetos são muitas vezes utilizados como fertilizantes em pomares, hortas, pastagens e lavouras em geral, devido a sua composição química, pois quando adicionados ao solo são absorvidos pelas plantas do mesmo modo que os fertilizantes comerciais, e quando aplicados corretamente podem suprir completamente a necessidade nutricional da cultura presente na área, não sendo necessária a utilização de adubação química (SEGRANFREDO, 2000).

Entretanto, a transformação de um simples fertilizante orgânico em fonte poluidora ocorre de forma rápida e inesperada, sendo danosa ao meio ambiente e podendo contaminar os lençóis freáticos e cursos d'água por apresentar grande quantidade de carga orgânica e presença de microrganismos derivados dos resíduos das granjas (LAZARETTI et al., 2013).

Sendo assim, o correto manejo e tratamento dos dejetos das granjas suinícolas deve levar em consideração parte do processo produtivo, exigindo critérios para a escolha da tecnologia e o nível de tratamento desejado (SOUZA et al., 2009).

Esta revisão tem como objetivo discutir sobre os impactos causados pelos resíduos da suinocultura industrial sobre o meio ambiente, assim como, as alternativas para o armazenamento, tratamento e reuso destes resíduos de forma econômica e sustentável.

\section{DEJETOS E RESÍDUOS DA SUINOCULTURA}

Segundo Cavaletti (2014), os resíduos da criação de suínos são constituídos por fezes, urina, água desperdiçada pelos bebedouros, água gasta com higienização do local, resíduos da ração, pêlos, poeira, animais mortos, entre outros, sendo tecnicamente chamados de dejetos. Os suínos são animais monogástricos, incapazes de realizar a digestão completa do bolo alimentar, sendo que aproximadamente $30 \%$ dos alimentos ingeridos saem nos dejetos e alguns nutrientes chegam a $90 \%$ de perda.

A água utilizada no manejo de limpeza aumenta o volume dos resíduos, e pela falta de tratamento adequado, se transforma em uma grande fonte poluidora dos mananciais, sendo que, criações intensivas e de confinamento concentram grande número de animais em áreas pequenas, aumentando o risco de contaminação da área ambiental. Uma granja de ciclo completo e de tamanho médio com 300 matrizes equivale à poluição de uma cidade de 75 mil habitantes. De acordo com a Associação Brasileira da Indústria Produtora e Exportadora de Carne Suína - ABIPECS 
(2013), o Brasil ocupa a posição de um dos maiores poluidores, decorrente do crescimento da atividade de produção de carne suína e, consequentemente, de seus resíduos.

A quantidade total de dejetos produzida por um suíno pode variar de acordo com sua categoria, sendo que animais de 15 a $100 \mathrm{~kg}$ podem produzir cerca de sete a oito litros de dejetos líquidos por dia em média (Tabela 1). O efeito direto e imediato se refere diretamente ao processo de contaminação acima dos níveis toleráveis, tanto dos solos agrícolas quanto das fontes hídricas.

Tabela 1- Quantidade média de dejetos produzida pelo suíno em diferentes fases de vida

\begin{tabular}{lccc}
\hline \multicolumn{1}{c}{ Categoria } & $\begin{array}{c}\text { Esterco } \\
\left(\mathbf{k g} / \mathbf{d i a}^{-1}\right)\end{array}$ & $\begin{array}{c}\text { Esterco e Urina } \\
\left(\mathbf{k g} / \mathbf{d i a}^{-1}\right)\end{array}$ & $\begin{array}{c}\text { Dejeto Líquido } \\
\left(\mathbf{L} / \text { dia }^{-1}\right)\end{array}$ \\
\hline Suínos de 25 a 100 kg & 2,30 & 4,90 & 7,00 \\
Porca em gestação & 3,60 & 11,00 & 16,00 \\
Porca em lactação + leitegada & 6,40 & 18,00 & 27,00 \\
Cachaço & 3,00 & 6,00 & 9,00 \\
Leitões Creche & 0,35 & 0,95 & 1,40 \\
\hline \multicolumn{1}{c}{ Média } & 2,35 & 5,80 & 8,60 \\
\hline
\end{tabular}

Fonte: Adaptado de Oliveira et al. (1993), citado por Cavaletti (2014).

De acordo com Konzen (2003), na suinocultura são encontrados dejetos com diferentes teores de sólidos e líquidos, sendo que essa variação depende do sistema de criação dos animais. Em criação de suínos em cama sobreposta podem ser encontrados cerca de $78,5 \%$ de dejetos sólidos em relação à fração líquida na cama, mas grande parte das granjas criadoras de suínos produz dejetos líquidos com sólidos que podem variar entre 1,7\% a 3,0\%, e em outras granjas é comum encontrarem teores de sólidos que variam entre 3,0\% a 4,5\%. Dessa forma, pode-se afirmar que essas medidas podem variar dependendo do fator tempo e exposição do resíduo sólido com a água para que ocorra ou não a diluição dos dejetos.

De acordo com Cavaletti (2014), a composição dos dejetos dos animais é diferente a cada etapa da criação, pois os teores nutricionais das rações são diferentes em cada fase de vida. 0 autor ainda destaca que os dejetos líquidos de suínos se caracterizam por elevada carga de matéria orgânica, nitrogênio $(N)$, fósforo $(P)$, potássio $(K)$, zinco $(\mathrm{Zn})$, cobre $(\mathrm{Cu})$, cálcio $(\mathrm{Ca})$, sódio $(\mathrm{Na})$, magnésio $(\mathrm{Mg})$, manganês $(\mathrm{Mn})$ e ferro (Fe), sendo grandes contaminantes biológicos que podem causar grave impacto ambiental.

Entre as principais substâncias poluentes estão $\mathrm{N}$ e $\mathrm{P}$, sendo o $\mathrm{N}$ o mais perigoso entre os elementos, pois se transforma em nitrato e facilmente se movimenta no solo atingindo o lençol freático, podendo poluir o meio ambiente na forma de amônia ou de óxido nitroso, que afeta a camada de ozônio (GRAZIANO, 2008). A grande contaminação de pequenas propriedades se dá pela grande concentração de N, P e K, que são descartados ao meio ambiente sem nenhum tipo de tratamento ou com manejo deficiente e incorreto.

Os meios de descarte dos dejetos ainda são bastante estreitos, pois poucos produtores conhecem alternativas para sua utilização, a não ser pela adubação orgânica que, na maioria das vezes provocam a contaminação do solo e das fontes hídricas que abastecem o meio rural e o meio urbano (SILVA et al., 2015).

\section{IMPACTOS CAUSADOS AO SOLO}

A contaminação do solo se inicia pelo descarte de dejetos de maneira irracional, pois é disponibilizada grande quantidade de nutrientes juntamente com microrganismos, podendo ser ou não patógenos (EPAGRI, 1995). Desse modo, pode ocorrer o acúmulo de nutrientes no solo provocando um desequilíbrio químico, com altos teores de $\mathrm{N}$ e $\mathrm{P}$, proporcionando uma possível redução em número de cultivares devido à sensibilidade que cada planta possui. Também pode causar intoxicação em animais pela grande quantidade de nutrientes presentes nas forrageiras, 
como o excesso de cobre e metais pesados, sendo totalmente prejudicial para animais, em especial para carneiros (SEGANFREDO, 1999).

Ainda de acordo com Seganfredo (1999), adubações orgânicas de origem suína podem ser mais agressivas que os adubos químicos ao solo, pois possuem composição química variável, apresentando uma ampla quantidade e diferentes teores de nutrientes. Com a adubação diária ou anual, os dejetos podem alterar a fertilidade, a composição estrutural, além de prejudicar os microrganismos existentes no solo, afetando principalmente a produção de plantas, que poderá ser maior ou menor, dependendo da composição dos resíduos, do total aplicado e do tipo do solo em utilização.

Os dejetos da suinocultura possuem uma elevada concentração de nutrientes, no entanto, o seu armazenamento deverá ser de, no mínimo, 120 dias para futura adubação orgânica. Durante esse tempo o material não deve ser armazenado utilizando-se materiais impermeabilizantes de má qualidade ou impróprios para esse propósito, pois se houver rupturas ocorrerá a infiltração do dejeto para o solo permitindo a sua contaminação. Quando a contaminação do solo ocorre de maneira vagarosa, não há consequências imediatas, mas a longo prazo, os efeitos são severos podendo ser irreversíveis (CAVALETTI, 2014).

Cada nutriente possui particularidade específica na mobilidade no perfil do solo, sendo que essa taxa de mobilidade irá depender da formação do nutriente e das características do solo que possuem a capacidade de interferir na disponibilidade e mobilidade dos nutrientes (SCHERER et al., 2010).

Basicamente a contaminação dos nutrientes ao ambiente se dá pela forma orgânica, caracterizado pela rápida capacidade de mobilidade entre o perfil do solo, diferentemente dos nutrientes químicos industriais. Estudos realizado por Scherer et al. (2007), observaram a mobilidade do $\mathrm{P}$ no perfil do solo, e constataram que em solos adubados com dejetos suínos o mineral apresentou maior capacidade de percorrer os horizontes do solo em comparação a áreas adubadas com adubo mineral.

$\mathrm{Na}$ forma orgânica os nutrientes podem percorrer todos os horizontes do solo em um pequeno espaço de tempo, podendo atingir o lençol freático e prejudicar e inviabilizar o seu consumo. Scherer et al. (2007) afirmam que por meio da adubação com dejetos suínos o risco de alguns nutrientes atingirem o lençol freático se torna alto, pela rápida movimentação pela forma orgânica. Entretanto, deve-se levar em conta as características dos solos, que podem interferir nesta mobilidade.

O principal problema da contaminação do solo acontece quando o solo consegue transmitir a sua toxidez para a planta, ocorrendo o fenômeno chamado de cadeia de alimentação, ou seja, quando o solo transmite a sua contaminação para planta e da planta para os animais e para o homem (SEGANFREDO et al., 2003).

A poluição do solo pelos dejetos suínos vem se agravando com o tempo e estudos sobre o aproveitamento dos dejetos como fonte de alimento para os animais, como peixes, bovinos de corte e para os próprios suínos, devido ao seu alto valor nutritivo de aproximadamente 12 a $18 \%$ de PB já foram realizados, entretanto, não vem sendo utilizado pela preocupação do dejeto ser um vetor de patógenos de doenças (ABCS, 2011).

\section{IMPACTOS CAUSADOS À ÁGUA}

Os impactos causados pela contaminação dos dejetos nos recursos hídricos são incalculáveis, afetando desde cursos de água subterrâneos, como bacia hidrográfica até cursos de água superficiais como córregos, lagoas e rios (PERDOMO, 2001).

A contaminação da água pelos dejetos suínos proporciona a redução do oxigênio dissolvido, disseminação de patógenos, contaminação das águas potáveis pela carga de amônia e nitrato, além de diversos elementos tóxicos, causando o desequilíbrio ecológico. Os principais 
componentes dos dejetos suínos que afetam os recursos hídricos são as matérias orgânicas, nutrientes, bactérias fecais e sedimentos, sendo as bactérias e o nitrato os principais elementos que comprometem a qualidade hídrica subterrânea e superficial (SILVA et al., 2015).

A fração hídrica é a mais contaminada entre todos os recursos ambientais, pois os dejetos suínos são manejados pela forma líquida, e dessa maneira, apresentam uma maior facilidade na mobilidade de elementos tóxicos da superfície do solo para as camadas mais profundas (lençóis freáticos). Ocorre então, a eutrofização dos cursos hídricos pela presença de grande quantidade de $\mathrm{N}$ e $\mathrm{P}$, além de atrair insetos e roedores pelo aspecto do mau cheiro que se forma nos cursos d'água (KUNZ, 2016).

Em um estudo realizado por Durigan et al. (2009), na região de Cinturão Verde do Município de Ilha Solteira-SP, foram visitadas 15 propriedades, sendo que 10 possuíam algum tipo de suinocultura onde foram encontradas 55 cabeças de animais desde leitões desmamados até animais de ciclo completo com uma produção estimada de 382,4 L/dia de dejetos. Nenhuma das propriedades adotava métodos de tratamento dos resíduos, os quais eram descartados diretamente ao solo. Muitas das granjas visitadas se localizavam próximas a cursos d'água, e análises das águas de rios indicaram que $93 \%$ dos pontos amostrados excederam os limites de Coliformes Totais (CT). Foram estimadas para a área 2,25 × 10^12 colônias, quantidade suficiente para contaminação do solo e dos cursos d'água, podendo inviabilizar a água para irrigação e consumo animal e humano.

De acordo com Pinto et al. (2014), quando ocorre o contato dos dejetos com os recursos hídricos pode haver prejuízo na qualidade da água, apresentando coloração escura e mau cheiro. Além disso, os resíduos dos suínos podem desencadear aparecimento de verminose, proliferação de moscas, morte de peixes e intoxicação da vegetação próxima ao curso d'água contaminado (GRAZIANO, 2008).

De acordo com diagnósticos realizados por Miyazawa et al. (2009), o sistema de tratamento e armazenamento de resíduos de suínos sem nenhum tipo de manutenção ou reparo pode proporcionar contaminação no solo, e uma possível contaminação da água subterrânea, sendo que, nitrato encontrado abaixo de $40 \mathrm{~cm}$ do solo é considerado um fator de contaminação do lençol freático.

\section{IMPACTOS CAUSADOS AO AR}

Além dos elementos solo e água, o ar também pode ser afetado pela contaminação dos dejetos suínos, principalmente devido à grande emissão do gás amônia (NH3). Além do NH3, outros gases também são produzidos pelos dejetos suínos provocando prejuízos nas vias respiratórias dos animais e do homem. Devido à emissão dos gases, pode ocorrer a formação de chuvas ácidas pela descarga de amônia para a atmosfera contribuindo para o aquecimento global (PERDOMO, 2001).

A principal fonte de indicação de problemas no ar se dá pelo forte odor podendo ser desagradável ou não, sendo que também existem gases nocivos que os humanos não conseguem identificá-los. No entanto, a formação do odor ocorre devido à volatilização dos compostos voláteis dos dejetos. Entre os gases contaminantes, os mais comuns são amônia, etanol, sulfeto de hidrogênio $\left(\mathrm{H}_{2} \mathrm{~S}\right)$, óxido nitroso $\left(\mathrm{N}_{2} \mathrm{O}\right)$, carbono sulfidro, dimetilsulfidro, metano, propanol e os ácidos graxos voláteis (SILVA et al., 2015).

Entre os gases produzidos pela volatilização dos dejetos suínos, dois são fundamentais para o efeito estufa, sendo óxido nitroso e metano. São comuns reportagens e matérias relacionadas ao efeito estufa destacando principalmente o gás carbônico $\left(\mathrm{CO}_{2}\right)$, no entanto, o metano possui carga poluente aproximadamente 30 vezes maior que o gás carbônico e o óxido nitroso corresponde a cerca de 300 vezes (GRZYBOWSKI, 2012). 
Os dejetos dos suínos são considerados grandes vetores de contaminação, principalmente para a própria espécie, pois a facilidade de disseminação de gases e agentes patogênicos pelo ar é grande, devido aos microrganismos poderem se mover pelo ar na forma de aerossóis ou em partículas de fezes, ração e pó suspensos. A circulação de vento pode distribuir gases, bactérias, pó e endotoxinas para um grande número de animais, pois nas criações intensivas existem vários animais compartilhando o mesmo espaço aéreo, e por este motivo problemas como pneumonia e infecção respiratória são encontradas com grande facilidade (BARCELLOS et al., 2008).

Aproximadamente $50 \%$ dos suínos mantidos em sistema de confinamento apresentam algum tipo de problema em seu sistema respiratório, devido ao contato de elevadas concentrações de gases flutuantes ou pela poeira. No entanto, as bactérias dos gêneros Streptococcus e Staphilococcus, entre outras, em ambiente fechado podem variar sua concentração entre 353.000 no inverno e 17.650 no verão por $\mathrm{m}^{3}$ de volume de ar. Em estruturas que possuem uma boa circulação de ar, esse número de microrganismos poderá ser menor, sendo em torno de 175.500 e 3.530 por $\mathrm{m}^{3}$ de volume de ar. De acordo com esses dados, a possibilidade de maior circulação de ar dentro da instalação pode adequar a quantidade de partículas suspensas e diminuir a concentração de gases no local (PERDOMO et al., 2001).

\section{IMPACTOS CAUSADOS À SAÚDE DOS ANIMAIS}

De acordo com Perdomo et al. (2001), o aumento de doenças em virtude da péssima qualidade do ar, da água e do solo vem aumentando juntamente com a expansão do sistema de criação de suínos.

A higiene das instalações é um fator chave para a criação de animais saudáveis, portanto, as instalações devem ser limpas e desinfetadas, de modo que evite a permanência de microrganismos e que não atraia outros animais para o interior das instalações, evitando vetores transmissores de doenças, como os ratos e moscas. Nas Américas são conhecidas 17 mil espécies de moscas, sendo que grande parte desses insetos são atraídos principalmente pelo odor emitido pelas fezes, vômitos e secreções. As moscas são insetos capazes de realizar a degradação de matéria orgânica e sobrevivem em locais infestados de agentes patogênicos, como bactérias, fungos e vírus. Deste modo, podemos considerar a mosca como vetor de agentes patogênicos que são comumente encontrados em locais que possuem manejo incorreto de resíduos de animais associados à falta de higiene do local (DELLATORRE, 2010).

Da mesma forma que as moscas, os ratos são grandes vetores de transmissão de doenças e agentes patogênicos, sendo conhecidas pouco mais de 2.000 espécies na natureza e somente três apresentam relação com o homem. Os ratos e camundongos apresentam uma extraordinária capacidade de adaptação ao ambiente, podendo sobreviver e reproduzir em locais inusitados e complexos. Deste modo, a presenças destes animais em uma granja suinícola já seria esperada, pois a maioria das granjas apresenta condições ideais para permanência e sobrevivência dos animais, além de encontrar alimentos de fácil acesso e ausência de predadores. Os ratos são animais responsáveis pela grande perda na produção de suínos devido à contaminação dos alimentos por fezes e urina ou pela destruição de máquinas, tubulações, fiações elétricas entre outros equipamentos e materiais, além de transmitir várias doenças, tais como, leptospirose, peste, tifo murino, salmonelose, febre da mordedura, triquinelose, entre outras (GRINGS et al., 2006).

Algumas doenças são facilmente transmitidas para os suínos, principalmente para os mais jovens, pelo contato com animais voadores ou por animais vetores de doenças que são atraídos para as granjas geralmente pela baixa higiene encontrada no local. Destaca-se a Pneumonia Enzoótica, causada pela bactéria Mycoplasma pneumoniae, presente em cerca de $90 \%$ do rebanho nacional, sendo encontrada com facilidade em instalações que apresentam grande falta de 
higiene, principalmente pelo acúmulo de fezes nas baias ou nas paredes do alojamento dos animais.

Outras doenças também podem ser encontradas devido à baixa higiene ou pela deficiência na limpeza da área, sendo que a Peste Clássica ou Febre Suína é causada por vírus e induzem vômitos nos animais, crescimento debilitados, manchas azuladas na pele, esterilidade e abortos entre outros sintomas e é encontrada em áreas que possuem deficiência no tratamento dos resíduos. O Brasil possui áreas livres da Peste Clássica, no entanto, também existem outras regiões em que a doença permanece recorrente e endêmica. A Pseudoraiva, também conhecida por Doença de Aujeszky, é uma doença causada por vírus podendo atacar outros animais além dos suínos, sendo que apenas os suínos possuem chances de sobreviver após a infecção. O modo mais eficaz de evitar a transmissão desta doença seria a higienização e desinfecção das instalações e impedir o contato dos suínos com animais de outras espécies (SANTOS, 2016).

\section{MANEJO DOS DEJETOS}

A preocupação com a preservação ambiental é de nível mundial, sendo então preocupação básica de qualquer sistema de produção, em que o manejo dos dejetos e rejeitos de animais não contamine o ambiente. Para evitar problemas de contaminação do solo e água, os dejetos devem ser usados como adubo orgânico respeitando sempre as limitações impostas pelas suas características, assim como do solo, água e planta. Quando houver área insuficiente para o tratamento dos dejetos devem-se buscar meios que permitam a retirada do material da área, de modo que não afete o sistema de produção dos animais e a saúde ambiental. Esses dejetos devem ser destinados para outros locais onde serão tratados corretamente, de modo que não ofereçam risco de poluição ao retornarem ao meio natural, de acordo com o órgão de fiscalização ambiental (EMBRAPA, 2015).

De acordo com Campos (2016), quando os dejetos são manejados adequadamente deixam de ser poluentes e passam a ser uma valiosa fonte de fertilizante, além de preservar e melhorar as propriedades física, química e biológica do solo, evitando a utilização de insumos derivados do petróleo que são altamente energéticos e caros.

Kunz et al. (2005), afirmam que em nosso país são utilizadas diversas tecnologias para o manejo e tratamento dos resíduos, sendo os mais utilizados os sistemas de esterqueiras e lagoas de estabilização em série. Cada método possui sua particularidade, sendo que nesta revisão serão destacadas as técnicas de bioesterqueira e a esterqueira convencional, biodigestão, lagoas de estabilização e a compostagem.

\section{Esterqueira e Bioesterqueira}

A utilização de esterqueira ou bioesterqueira é recomendada para produtores que possuem áreas de plantação extensas, ou seja, lavouras, pastagens ou pomares grandes o suficiente para que os resíduos sejam utilizados como forma de fertilizantes orgânicos. Esse método é de baixo custo de aplicação e impede que os dejetos sejam lixiviados pelo solo. Entretanto, é recomendado para o tratamento de resíduos de granjas que não possuam grande quantidade de nutrientes contaminantes, como o N, P, Cu e Zn, pois as altas concentrações desses nutrientes podem causar grande impacto ambiental quando o resíduo é manejado de forma errônea ou por deficiência da tecnologia empregada (AFONSO et al., 2014).

As esterqueiras possuem como objetivo o armazenamento dos resíduos líquidos, sendo que seu período mínimo de armazenamento deve ser de 120 dias, com temperatura média de $19{ }^{\circ} \mathrm{C}$ ao longo de todo dia, sendo possível a variação de temperatura devido a oscilação da temperatura externa podendo chegar de $10^{\circ} \mathrm{C}$ a $24 \stackrel{\circ}{ } \mathrm{C}$, e com pH em torno de 7,0 , podendo variar de 7,0 a 7,45, em média. Este período de tempo de 120 dias permite uma pequena fermentação 
aeróbia e uma estabilização dos dejetos até o momento correto para aplicação ao solo (KUNZ et al., 2004).

A esterqueira possui estrutura simples similar a grandes trincheiras e possui apenas uma câmara de armazenamento de dejetos, diferente das bioesterqueiras, que contêm duas câmaras possuindo como base o biodigestor indiano (RANZI; ANDRADE, 2004). Geralmente, o abastecimento das câmaras ocorre diariamente até alcançar o volume máximo de armazenamento de dejetos ou quando o esterco estiver maturado o suficiente para ser empregado como fonte de enriquecimento do solo (FERREIRA et al., 2014).

O modelo de bioesterqueira contém duas câmaras, sendo que o fluxo de entrada e armazenamento dos dejetos suínos ocorre na primeira câmara. Em seguida, o material sofre fermentação e segue para a segunda câmara, onde ocorrerá o seu armazenamento e continuam fermentando.

A construção da esterqueira ou bioesterqueira necessita atender à capacidade de receber e armazenar os dejetos durante, no mínimo, 120 dias. Portanto, deverá ser planejada de acordo com o total aproximado de produção diária de dejetos, de forma que não ocorra mau funcionamento do sistema. Os materiais utilizados para construção podem ser de solocimento, alvenaria, lona especial de PVC, geomembranas em PVC, pedras argamassadas ou PEAD (BELLI FILHO et al., 2001).

Diferente dos demais métodos, as bioesterqueiras e esterqueiras convencionais não possuem como intuito o tratamento propriamente dito, sendo utilizado como sistema de armazenamento de resíduos suínos do início da produção até o limite de estocagem de ambas. Após chegar ao limite de armazenamento, os resíduos poderão ser lançados ao solo como fonte de fertilizante agronômico, sendo que, é necessário que o material depositado na bioesterqueira ou esterqueira tenha alcançado o tempo mínimo de 120 dias.

Ambas as tecnologias apresentam resultados similares, sendo que a esterqueira apresenta investimento e manutenção inferior à bioesterqueira, no entanto a bioesterqueira apresenta facilidade operacional e maior armazenamento em relação à esterqueira (BELLI FILHO et al., 2001).

Estudos comparativos com bioesterqueira e esterqueira para armazenamento e valorização dos dejetos de suínos foram realizados por Gosmann (1997) em duas etapas (de julho a novembro e de novembro a março). Os resultados comprovaram eficiências semelhantes na redução da matéria orgânica e na produção do poder fertilizante ( $N, P$ e K) das duas tecnologias, entretanto a esterqueira apresentou a vantagem de um custo de construção e de operação $20 \%$ inferior ao da bioesterqueira.

\section{Lagoas de Estabilização}

Existem diversas séries de lagoas de estabilização de dejetos suínos, mas o sistema mais utilizado consiste na lagoa anaeróbia seguida de lagoa facultativa (sistema australiano) (ZORDAN et al., 2008).

Há necessidade de isolamento de cada etapa, de modo que cada sequência aconteça individualmente para garantir o maior valor agronômico e banimento de agentes patogênicos. Ou seja, o afastamento entre as fases é essencial para minimizar a sobrecarga das estações de tratamento (HIGARASHI et al. 2011).

O decantador de palheta é considerado a peça chave para todo o processo de tratamento e possui como objetivo realizar a separação das fases líquida e sólida dos resíduos produzidos pela granja (PERDOMO et al., 1999). Nessa primeira fase ocorre um grande acúmulo de dejetos sólidos e uma considerável formação de lodo proveniente da fração liquida, sendo que o lodo representa aproximadamente 10 a $15 \%$ de todo volume que será passado pelo decantador. Recomenda-se realizar a retirada do lodo formado no decantador a cada dois dias, sendo que este lodo poderá ser tratado na esterqueira para ser utilizado como fonte de adubação orgânica e a fração liquida 
será canalizada para lagoa anaeróbica para continuar o processo de tratamento dos poluentes. O decantador consegue extrair aproximadamente $48 \%$ da matéria seca, $20 \%$ de N, $18 \%$ de K, 39\% de $\mathrm{P}, 45 \%$ da carga orgânica $\left(\mathrm{DBO}_{5}\right)$ e $27 \%$ dos coliformes fecais presente no resíduo (PERDOMO et al., 1999; SILVA et al., 2011).

A principal finalidade das lagoas anaeróbias é a remoção de DBO e de sólidos em suspensão. Estes sólidos são sedimentados no fundo da lagoa, sendo digeridos, posteriormente, pela ação das bactérias anaeróbias (SILVA FILHO, 2007).

As lagoas anaeróbias apresentam grande desenvolvimento de bactérias responsáveis pela fermentação, ocorrendo a formação de ácidos devido, principalmente às bactérias acidogênicas, sendo que ocorre também a produção de metano devido à atividade das bactérias metanogênicas. No primeiro momento, ocorre a perda do oxigênio e transformação de compostos orgânicos em conteúdos simples, como ácido orgânico, no qual ocorre a produção de mau cheiro devido ao gás sulfídrico e mercaptana em pH abaixo de 6. No segundo momento, ocorre a modificação do ácido orgânico em metano $\left(\mathrm{CH}_{4}\right)$ e dióxido de carbono $\left(\mathrm{CO}_{2}\right)$, com o aparecimento da coloração cinzenta no conteúdo da lagoa e formação de mau odor contínuo, com pH entre 7 a 7,5 e temperatura aproximada de 15 ㅇ C (RIZZONI et al., 2012). Neste tipo de lagoa, a redução de coliformes não é significativa, quando comparadas com as facultativas e de maturação (SILVA FILHO, 2007).

As lagoas anaeróbias normalmente são construídas em elevado grau de profundidade (em torno de 4 a 5 metros de profundidade e 3 metros para largura e comprimento), sendo necessário que comporte todo resíduo oriundo da suinocultura de modo que não permita a transição do oxigênio da camada superficial para a camada inferior (MEDRI et al., 1996).

Após a estação de tratamento anaeróbica há necessidade de outra estação, a lagoa facultativa, e sua finalidade consiste em retirar parte dos compostos orgânicos provenientes da lagoa anaeróbica. Esse tratamento poderá ocorrer em três estados, zona anaeróbia, zona facultativa e aeróbia. Recomenda-se construir esta lagoa em profundidade em torno de 1 a 1,5 metros, para favorecer o desenvolvimento de algas (organismos vegetais) e bactérias anaeróbias (VIVAN et al., 2010).

De acordo com ABCS (2011), a camada orgânica flutuante de tamanho menor será destinada ao tratamento aeróbio com alta concentração de oxigênio dissolvido, devido à fotossíntese das algas e pela troca de gases da parte superior da lagoa com atmosfera. Portanto, a matéria orgânica de tamanhos maiores será sedimentada na porção mais profunda da lagoa, formando uma espessa camada de lodo ao fundo e recebendo tratamento anaeróbio. A matéria orgânica sedimentada no meio da lagoa será colonizada por bactérias facultativas, que podem sobreviver na ausência ou na presença de oxigênio.

A lagoa facultativa consiste em remover cerca de 40 a $45 \%$ do $\mathrm{DBO}_{5}$ restantes da lagoa anaeróbia e cerca de $40 \%$ dos sólidos totais, $28 \%$ de $\mathrm{P}, 57 \%$ de $\mathrm{N}$ e $97,3 \%$ de coliformes. $\mathrm{O}$ final do processo da lagoa facultativa ocorre geralmente entre 15 a 25 dias, mas pode-se estender este tratamento por 30 a 45 dias para melhor resultado. Deve ser localizada em locais distantes de residências e áreas de criação de animais devido a problemas de odores liberados pela lagoa (DIAS, 2011).

Após o processamento facultativo, o volume de nutrientes e patógenos presentes estão relativamente baixos, mas ainda não se encontram entre os padrões de lançamento estabelecidos pela legislação ambiental. É considerado como aceitável a água que tratada por qualquer meio de tratamento apresente 1.000 coliformes fecais $/ 100 \mathrm{~mL}$ ou 1.000 E. coli/100 mL para utilização agronômica, sendo necessário utilizar outra etapa de tratamento para que possa eliminar grande parte de microrganismos e materiais indesejáveis presentes (CONAMA, 2005).

A lagoa de maturação possui eficácia no tratamento de acabamento final, ou seja, na finalização do tratamento da água oriunda de passagem de outras lagoas. Apresenta boa remoção de grande parte dos patógenos, sendo mais barata em relação a outros meios de tratamento, 
como a desinfecção por cloração, e apresenta capacidade de remoção de coliformes em torno de 99,5\%, proporcionando capacidade para a reutilização da água para fins de irrigação ou para eliminação em corpos d'água (OLIVEIRA, 2014).

O tratamento da lagoa de maturação pode sofrer efeitos negativos devido a fatores como velocidade de vento, tempo de iluminação e regime de atuação das bactérias existentes no tratamento, sendo assim, a construção da lagoa deve ser realizada de forma que amenize efeitos que poderão comprometer a sua eficiência. Por conta de sua construção em profundidade baixa (entre 1,0 a 1,5 m) os raios ultravioletas (radiação solar) serão mais efetivos juntamente com elevado pH e elevada concentração de oxigênio dissolvido, o que contribui para uma desinfecção natural, promovendo eficiência e rapidez do sistema. A água em tratamento deverá permanecer na lagoa entre 3 a 5 dias, dependendo da taxa hidráulica atuante (SILVA, 2003).

A utilização de lagoas de estabilização em série com associação da lagoa anaeróbia, facultativa e maturação consegue em conjunto uma elevada capacidade de retirada de matéria orgânica e coliformes, que podem chegar em média a 99,99\%. Desse modo, abrange valores possíveis para a utilização d'água para fins agrícolas ou disposição em corpos d'água, de acordo com a resolução do CONAMA no 20 de 1986 (BRASIL, 1986).

\section{Composteira}

O sistema de compostagem consiste no tratamento biológico natural para reciclagem de nutrientes presentes nos dejetos e resíduos de suínos, com a transformação de resíduos líquidos em compostos sólidos, com maior valor agronômico (CADIS; HENKES, 2014).

Como todo meio de tratamento de resíduo, a composteira deve possuir material impermeabilizante em desnível evitando o acúmulo de chorume e a possível contaminação do solo e dos lençóis d'água. Pode ser construída com uma altura de 2 metros e largura em torno de 2 a 2,5 metros, sendo que as paredes podem estabelecer uma altura em torno de 1,60 metros de altura de modo que evite a entrada de animais e permita grande circulação de vento para eliminar o vapor da água em evaporação (PAIVA, 2016).

De acordo com ABCS (2014), a composteira se torna eficiente devido a elementos essenciais para o bom funcionamento e decomposição do material destacando a temperatura, nutrientes, $\mathrm{pH}$ e disponibilidade de $\mathrm{O}_{2}$.

Segundo Oliveira (2016), a primeira fase da compostagem chama-se impregnação, o qual consiste em espalhar uniformemente o material aerador no local a ser realizado o processo, que deverá possuir camadas de substrato em torno de $50 \mathrm{~cm}$ (mínimo) e várias séries de distribuição de dejetos. Depois da primeira incorporação, espera-se que o material aerador absorva todo o líquido, sendo necessário realizar a mistura para que ocorra melhor absorção. Após a primeira absorção, realiza-se novamente a incorporação de dejetos até atingir a capacidade máxima de absorção do substrato.

O material de aeração deve ser orgânico, seco e de boa fonte de carbono, destacando a maravalha, serragem, cama de aviário e palhadas de cultura (PAIVA et al., 2001).

Após a absorção do líquido, o material irá fermentar e aumentar sua temperatura em torno de 45 a 55 ํㅡ devido à presença de bactérias e fungos no meio. A elevação da temperatura irá promover a evaporação do líquido que foi absorvido pelo substrato gradativamente.

A segunda fase se chama maturação, onde acontecerá o final do procedimento de compostagem, em que ocorre a estabilização do material em temperatura em torno de 60 a 70 ㄷ. . A alta temperatura associada ao revolvimento do material, que deverá ser realizado a cada três dias, permite a eliminação de agentes patogênicos e formação de nutrientes por meio da decomposição do material orgânico provocado pela fermentação de bactérias e fungos. Este período deve possuir no mínimo 45 dias (SERPA FILHO et al., 2013). 
Alguns nutrientes podem ser perdidos na forma de chorume, que é o líquido originado da decomposição de todo material orgânico. Deste modo, a composteira deve ser construída com piso em desnível para que todo chorume escoe para a parte externa, podendo retornar para o composto juntamente com os dejetos ou diluído para adubação agrícola, sendo extremamente rico em nutrientes e sais minerais. Pelo processo de compostagem o chorume se torna um excelente adubo natural e de fácil utilização, podendo ser utilizado em rega das plantas ou borrifado na superfície das folhas (CADIS; HENKES, 2014).

A composteira é considerada um ótimo sistema de tratamento de dejetos suínos, sendo que a Lei Federal no 12.305/2010, em seu Art. 3ㅇ possibilita a utilização da composteira para o tratamento de cadáveres suínos entre outros resíduos biológicos (BRASIL, 2010).

A compostagem de carcaças é bastante similar ao sistema de compostagem de dejetos, mas apresenta algumas diferenças, como a temperatura no interior da composteira que deve variar entre 48 a 65으, desencadeando o surgimento de bactérias termofílicas (PAIVA, 2016).

Para o bom funcionamento da compostagem de cadáveres deve haver uma camada de material carbonáceo no fundo da cela da composteira em torno de $30 \mathrm{~cm}$, podendo ser maior de acordo com o tamanho e peso do material. Após o depósito da carcaça, deverá ser colocado uma boa cobertura para evitar efeitos indesejáveis como a baixa relação de $\mathrm{C}: \mathrm{N}$, baixa temperatura interna e produção de odores. O composto deve apresentar temperatura interna em torno de 55 a $65^{\circ} \mathrm{C}$, sendo que a pilha não deverá ser revirada antes de 90 dias devido ao mau cheiro e risco de exposição. Após os 90 dias termina o estágio termofílico e ocorre a queda da temperatura, podendo-se misturar o composto, e dá-se o início ao segundo estágio, chamado de maturação. Neste estágio ocorre a predominância de Actinomicetos e fungos que trabalham em temperatura em torno de $45^{\circ} \mathrm{C}$, com duração de 28 dias, sendo que nesse período ocorre a baixa taxa de decomposição biológica e a degradação da lignina e lignocelulose do material aerado (SILVA; RODRIGUES, 2014).

Em relação à granulometria, quanto menor o tamanho das frações maior será a superfície das partículas para ação dos microrganismos. No entanto, as carcaças dos suínos não necessitam ser totalmente abertas, pois desmembramentos e cortes no abdômen e tórax e em torno de todo material são suficientes para adequada degradação do material (ABCS,2014).

Para evitar resultados indesejados, deve-se atentar à temperatura durante todo processo, pois por meio dela podemos diagnosticar atividade biológica presente no material em decomposição. Ao identificar dificuldade em atingir a temperatura, diversos fatores poderão estar influenciando, tais como, pilha muito seca que poderá ser corrigida com uma nova incorporação de dejetos no composto, pilha muito úmida que poderá ser corrigida adicionando nova camada de substrato, substrato mal misturado que deverá ser novamente misturado corrigindo os locais que não foram mexidos (DIAS et al., 2016).

\section{Biodigestor}

Além da capacidade do biodigestor de transformar material orgânico em fontes renováveis, o mesmo contém capacidade considerável na redução orgânica, podendo atingir valores em torno de $96 \%$, reprimindo a quantidade de $\mathrm{P}$ total (40\%), Cu total (40\%) e Zn total (22\%). Com a adição de agentes de biorremediação (bactérias) as reduções podem atingir valores de 91, 96 e 97\%, respectivamente para $P$, Cu e Zn (BRAGA, 2006).

Estudos realizado por Laslowski (2004), comprovaram que um suíno produz em média 2,3 $\mathrm{kg}$ de dejeto por dia. Considerando que em quatro dias produza $9 \mathrm{~kg}$ de dejetos, lançando esse volume em um sistema de biodigestor, ele será capaz de produzir $1 \mathrm{~m}^{3}$ de biogás, correspondendo a 0,61 $\mathrm{L}$ de gasolina, $0,55 \mathrm{~L}$ de diesel, $0,58 \mathrm{~L}$ de querosene, $0,45 \mathrm{~L}$ de gás de cozinha, $0,79 \mathrm{~L}$ de álcool, 1,43 kW e 1,53 kg de lenha. 
Portanto, o tratamento de dejetos por digestão anaeróbia biodigestora se constitui em uma alternativa bastante positiva, pois além de atuar na redução de emissão dos gases poluentes para a atmosfera, redução de custo com energia elétrica, devido à produção do biogás, e na destruição de alguns organismos patogênicos e parasitas presentes nos dejetos suínos, proporciona parcial condição para utilização do biofertilizante em áreas agrícolas (SANTOS; NARDI JúNIOR, 2013).

O tratamento dos resíduos pode durar em média 30 dias, mas depende de diversos fatores, tais como, pH, temperatura interna, pressão, atividade microbiana, composição dos dejetos, tamanho de dejetos sólidos, total anaerobiose, tipo de biomassa existente, entrada de antibiótico, inseticida, desinfetante entre outros (BERTONCINI, 2011).

O biodigestor é composto de duas estruturas, sendo a primeira câmara (tanque) onde acontece a degradação dos resíduos por fermentação anaeróbica, que produz o biofertilizante, e a segunda estrutura, chamada de gasômetro (campânula), que armazena produtos gasosos, como o dióxido de carbono, sulfídrico, metano, entre outros gases (DOTTO; WOLFF, 2012).

O biogás, produzido pelas bactérias anaeróbicas, é utilizado para diversos meios, sendo um combustível energético gasoso semelhante ao gás natural, podendo ser utilizado como fonte de energia elétrica, térmica ou mecânica. A utilização do biogás deve ser imediata, pois possui em sua composição agentes como $\mathrm{CO} 2$, vapor d'água e gases corrosivos, que quando armazenados provocam redução significativa da vida útil do equipamento utilizado (EMBRAPA, 2015).

De acordo com Frigo et al. (2015), no Brasil existem quatro padrões de biodigestores, sendo o modelo chinês, indiano, canadense e batelada. A diferença entre os três modelos consiste basicamente em sua construção e tipo de cúpula. O modelo chinês é todo construído em alvenaria, sendo indicado para propriedades pequenas, pois não ocupa espaço em sua superfície, por ser soterrado ao solo, desta maneira é possível se cultivar em seu entorno. O biogás é suavizado do interior do biodigestor devido à pressão exercida pelo biofertilizante localizado na descarga (SALES FILHO, 2014).

O modelo indiano conta com uma cúpula de ferro e móvel, podendo se movimentar para baixo ou para cima de acordo com a produção de biogás. Esta habilidade de movimentação da cúpula impulsiona o biogás produzido no interior do biodigestor para as encanações que alimenta os equipamentos da propriedade. Sua estrutura é composta por uma parede central que serve para dividir o tanque de fermentação em duas câmaras, fazendo com que o material em fermentação possa circular no interior do biodigestor (TARRENTO; MARTINES, 2006).

O modelo canadense contém largura maior do que seu tamanho, sendo construído na horizontal, desta forma apresenta maior exposição de sua área aos raios solares apresentando uma maior produção de biogás em relação aos demais citados. Este modelo de biodigestor conta com uma cúpula de plástico maleável, inflando devido à produção de gases, sendo que pode ser abastecido de forma diária ou única. É comum adicionar pesos na superfície da cúpula deste modelo de biodigestor para impulsionar o biogás para saída. Este modelo de biodigestor é mais utilizado em todo Brasil, devido a sua utilização tanto em pequenas quanto em grandes propriedades e em projetos agroindustriais (OLIVER, 2008).

De acordo com Frigo et al. (2015), o biodigestor modelo batelada é composto por um sistema simples, e a sua construção poderá ser feita com apenas um tanque anaeróbio ou diversos tanques em série. $O$ abastecimento deste modelo é realizado de uma única vez, não podendo realizar abastecimento contínuo ou diário, pois deste modo prejudicará a fermentação do substrato e a formação de biogás. A biomassa permanecerá no interior do biodigestor até esgotar a capacidade total de produção de biogás, sendo considerado assim o final do ciclo do biodigestor. Devido ao seu abastecimento ser de uma única vez, é recomendado a utilização deste modelo de biodigestor para o tratamento de cama e resíduos da atividade de granjas avícolas de corte. 
O biodigestor promove tratamento satisfatório dos dejetos suínos, porém é necessário outro meio de tratamento para a finalização do processo (SILVA; FRANCISCO, 2010). Recomendase a utilização de lagoa de estabilização após a saída do resíduo da câmara biodigestora, deste modo evitando possíveis problemas ambientais e contaminação por patógenos, tais como, Salmonella spp., Escherichia coli, Shigella spp. e Klebsiella spp. Algumas bactérias possuem resistência e não são destruídas por meio da digestão anaeróbia (BEZERRA et al., 2014).

Vivan et al. (2010) ao avaliarem um sistema de tratamento de dejetos suínos composto por um biodigestor acoplado a um sistema de lagoas de estabilização verificaram que o sistema foi eficiente no abatimento da matéria orgânica com elevada remoção de $\mathrm{Cu}$, Zn e P. Os baixos custos de implantação e de operacionalização tornam o sistema atrativo, embora ele ainda necessite de uma maior capacidade de remoção de nutrientes e maior eficiência durante os meses de inverno.

\section{CONSIDERAÇÕES FINAIS}

O uso irracional dos resíduos provenientes de uma suinícola provoca amplo impacto ao meio ambiente, podendo levar à contaminação do solo, ar, água e sistemas de produção pela presença de microrganismos e pela grande quantidade de nutrientes presentes nos resíduos. Desta forma, o uso de sistemas de tratamentos, como esterqueiras, biodigestores, lagoas estabilizadoras em série e composteiras são sistemas indispensáveis para o manejo e tratamento dos resíduos da produção intensiva de suínos, com eliminação da sua carga poluente e possibilidades de utilização do resíduo orgânico para uso agronômico.

O sistema de tratamento a ser adotado dependerá das características de produção e instalações da granja, sendo indispensável o planejamento por meio da estimativa da quantidade de dejetos e qualidade dos efluentes levando-se em conta os parâmetros conteúdo de sólidos totais, sólidos voláteis e o teor de nutrientes presentes. Tais parâmetros são fundamentais para a escolha da tecnologia de tratamento ideal ao produtor, ou mesmo a associação de diferentes métodos que atendam à demanda dos sistemas de produção industrial de suínos.

\section{REFERÊNCIAS}

ABCS - ASSOCIAÇÃO BRASILEIRA DE CRIADORES DE SUINOS. Manual brasileiro de boas práticas agropecuárias na produção de suínos. Brasília-DF: ABCS, MAPA, Concordia: Embrapa Aves e Suínos, 2011.

ABCS - ASSOCIAÇÃO BRASILEIRA DE CRIADORES DE SUÍNOS. Produção de suínos: teoria e prática. 2014.

Disponível em: http://www.abcs.org.br/attachments/1823_Livro\%20Produ\%C3\%A7\%C3\%A3o.pdf Acessado em 06/06/2016.

ABIPECS - ASSOCIAÇÃO BRASILEIRA DA INDÚSTRIA PRODUTORA E EXPORTADORA DE CARNE SUÍNA. Estatísticas Mundiais - Produção e Exportação. 29 mar. 2013. Disponível em: http://www.abipecs.org.br/pt/estatisticas/mundial.html. Acessado em 13/05/2016.

AFONSO, E.R.; PALHARES, J.C.P.; GAMEIRO, A.H. Impacto de estratégias nutricionais no dejeto de suínos. São Carlos-SP: Embrapa Sudeste, 2014. Disponível em: http://posvnp.org/simposios/2014/resumos/AugustoHauberGameiro.pdf. Acessado em 07/05/2016.

BARCELLOS, D.E.S.N.; BOROWSKI, S.M.; GHELLER, N.B.; SANTI, M.; MORES, T.J. Relação entre ambiente, manejo e doenças respiratórias em suínos. Acta Scientiae Veterinariae. v.36 (Supl 1), p.87-93, 2008. 
BELLI FILHO, P.; CASTILHOS Jr., A.B.; COSTA, R.H.R.; SOARES, S.R.; PERDOMO, C.C. Tecnologias para o tratamento de dejetos de suínos. Revista Brasileira de Engenharia Agrícola e Ambiental, v.5, n.1, p.166-170, 2001. Disponível em: http://www.agriambi.com.br/revista/v5n1/166.pdf. Acessado em 30/08/2016.

BERTONCINI, E.I. Dejetos da suinocultura-desafios para o uso agrícola. Pesquisa \& Tecnologia, vol. 8, n.2, 2011.

BEZERRA, K.L.P.; FERREIRA, A.H.C.; CARDOSO, E.S.; MONTEIRO, J.M.; AMORIM, J.S.; SANTANA Jr., H.A.; SILVA, N. Uso de biodigestores na suinocultura. Revista Eletrônica Nutritime, artigo 275, v. 11, n. 5, p. 3714-3722, 2014.

BRAGA, V.C. Análise da viabilidade na implantação de biodigestores para tratamento e valoração de dejetos suínos na granja Brasil Agroceres Pic. Patos de Minas- MG:UNIPAM Centro Universitário de Patos de Minas, 2006.

BRASIL. Resolução CONAMA, 18 de junho de 1986. Classificação das águas doces, salinas e salobras do território nacional. Brasília, DF: Diário Oficial da Republica Federal do Brasil, p. 1135611361, 30 de julho de 1986.

BRASIL. Lei N. 12.305, de 2 de agosto de 2010. Institui a Política Nacional de Resíduos Sólidos; altera a Lei n. 9.605, de 12 de fevereiro de 1998; e dá outras providências. Disponível em: http://www.planalto.gov.br/ccivil_03/_ato2007-2010/2010/lei/l12305.htm. Acesso em 25/10/2016.

CADIS, P.; HENKES, J.A. Gestão ambiental na suinocultura: sistema de tratamento de resíduos líquidos por unidade de compostagem. Revista Gestão Sustentável Ambiental, v.3, n.1, p. 1-36, Florianópolis, 2014.

CAMPOS, A. T. Manejo dos dejetos. Agência de Informação EMBRAPA. Agronegócio do leite. Brasília/DF: $\quad$ EMBRAPA. $2016 . \quad$ Disponível em:http://www.agencia.cnptia.embrapa.br/Agencia8/AG01/arvore/AG01_250_21720039249.htm I. Acessado em 14/05/2016.

CAVALETTI, L.B. Avaliação do sistema de compostagem mecanizada para dejetos suínos. Lajeado: Centro Universitário Univates, UNIVATES, $2014 . \quad$ Disponível em:https://www.univates.br/bdu/bitstream/10737/581/1/2014LucianoBragaCavaletti.pdf. Acessado em 02/04/2016.

CONAMA. CONSELHO NACIONAL DE MEIO AMBIENTE. Resolução n.357, de 17 de março de 2005. Disponível em: http://www.mma.gov.br/port/conama/res/res05/res35705.pdf. Acessado em 09/06/2016.

DARTORA, V.; PERDOMO, C.C.; TUMELERO, I.T. Manejo de dejetos suínos. Boletim Informativo de Pesquisa e Extensão, n. 11, Concórdia-SC: EMBRAPA - CNPSA/EMATER/RS, 1998. 41p.

DELLATORRE, M.M. Problemas causados pelas moscas domésticas na produção animal. Jornal Dia de Campo. Sanidade Animal, $2010 . \quad$ Disponível 
em:http://www.diadecampo.com.br/zpublisher/materias/Materia.asp?id=21684\&secao=Sanidade \%20Animal. Acessado em: 05/06/2016.

DIAS, R. Gestão Ambiental: Responsabilidade Social e Sustentabilidade. 2 ed. São Paulo, 2011.

DIAS, C.P.; LEITÃO, F.O.; COSER, F.; SILVA, W.H.; OLIVEIRA, P.A.V. Tecnologias para o tratamento de dejetos suínos com vista à sustentabilidade. In: Feira da Indústria Latino-Americana de Aves e Suínos, AVESUI, Florianópolis-SC, $2016 . \quad$ Disponível em: http://www.agricultura.gov.br/arq_editor/Resumo\%20Expandido-2(1).pdf. Acessado em 16/06/2016.

DOTTO, R.B.; WOLFF, D.B. Biodigestão e produção de biogás utilizando dejetos bovinos. Ciências Naturais e Tecnológicas, Santa Maria, v.13, n.1, p.13-26, 2012.

DURIGAN, M.R.; FRANCO, R.A.M.; ROSATO, M.M.; HERNANDEZ, F.B.T.; LEITE, M.A. Potencial de contaminação de dejetos de suínos no Cinturão Verde do Município de Ilha Solteira-SP. Ilha Solteira/SP: FEIS/UNESP, Departamento de Fitossanidade, Engenharia Rural e Solos, 2009. Disponível em: http://www.agr.feis.unesp.br/pdf/3encivi_potencial_de_contaminacao_.pdf. Acessado em 16/05/2016.

EMBRAPA. Utilização de microalgas no tratamento dos dejetos suínos e geração de biogás. Rural Pecuária, São Jose do Rio Preto, 2015. Disponível em: http://ruralpecuaria.com.br/tecnologia-emanejo/novas-tecnologias/ embrapa-comprova-utilizacao-de-microalgas-no-tratamento-dosdejetos-suinos-e-geracao-de-biogas.html :Acesso em 12/10/2016.

EPAGRI. Aspectos práticos do manejo de dejetos suínos. Florianópolis: EPAGRI/ EMBRAPA-CNPSA, 106 p., 1995.

FERREIRA, D.C. Pós-tratamento de água residuária da suinocultura em sistemas alagados construídos combinados. UFLA - Universidade Federal de Larvas, Lavras - MG, 2012. Disponível em:

http://repositorio.ufla.br/bitstream/1/600/1/TESE\%20P\%C3\%B3stratamento\%20de\%20\%C3\%A1g ua\%20residu\%C3\%A1ria\%20da\%20suinocultura\%20em\%20sistemas\%20alagados\%20constru\%C3 \%ADdos\%20combinados.pdf. Acessado em 12/10/2016.

FERREIRA, A.H.; CARRARO, B.; DALLANORA, D.; MACHADO, G.; MACHADO, I.P.; PINHEIRO, R.; ROHR, S. Produção de suínos: teoria e pratica. $A B C S$, Integral, Brasília, 2014. 980p. Disponível em: http://www.abcs.org.br/attachments/1823_Livro\%20Produ\%C3\%A7\%C3\%A3o.pdf: Acessado em $12 / 10 / 2016$.

FRIGO, K.D.A.; FEIDEN, A.; GALANT, N.B.; SANTOS, R.F.; MARI, A.G.; FRIGO, E.P. Biodigestores: seus modelos e aplicações. Acta Iguazu, v.4, n.1, p. 57-65, 2015.

GOSMANN, H. A. Estudos comparativos com bioesterquera e esterqueira para armazenagem e valorização dos dejetos de suínos. 1997. 115 f. Dissertação (Mestrado em Engenharia Ambiental) Universidade Federal de Santa Catarina, Florianópolis. 
GRAZIANO, X. Chorume suíno. O Estado de São Paulo, 29/01/2008. Disponível em:http://www.revistameioambiente.com.br/2008/01/29/chorume-suino/. Acessado em $16 / 05 / 2016$.

GRINGS, V.H.; MONTICELLI, C.J.; PAIVA, D.P.; BORDIN, L.C. Controle integrado de ratos. Concórdia: Embrapa Suínos e Aves, 2006. 14p. Disponível em: http://www.cnpsa.embrapa.br/sgc/sgc_publicacoes/publicacao_c6g65n3m.pdf. Acessado em 05/06/2016.

GRZYBOWSKI, N. Manejo de dejetos de suínos - uma responsabilidade social. Com Arte, maio 2012. Disponível em: http://www.upf.br/comarte/?p=647. Acessado em 20/05/2016.

HIGARASHI, M.M.; OLIVEIRA, P.A.V.; MIRANDA, C.R. Meio ambiente baliza atuação da unidade a partir dos anos 90. In: SOUZA, J. C. P. V. B.et al. (Ed.). Sonho, desafio e tecnologia: 35 anos de contribuições da Embrapa Suínos e Aves. Concórdia: Embrapa Suínos e Aves, p. 271-289, 2011. Disponível em: https://www.alice.cnptia.embrapa.br/alice/bitstream/doc/908299/1/Meioambientebalizaatuacao .pdf. Acessado em 07/06/2016.

KONZEN, E. A. Fertilização de lavoura e pastagem com dejetos de suínos e cama de aves. Informe Técnico, V Seminário Técnico do Milho, Videira-SC: Embrapa, 2003. Disponível em: http://www.cnpms.embrapa.br/destaques/dejetos/InformeTecnicoDejetos.PDF. Acessado em $15 / 05 / 2016$.

KUNZ, A.; OLIVEIRA, P.A.V.; HIGARASHI, M.M.; SANGOI, V. Recomendações para uso de esterqueiras para armazenagem de dejetos de suínos. Comunicado Técnico, Concórdia-SC: EMBRAPA, $2004 . \quad$ Disponível em: https://www.agencia.cnptia.embrapa.br/recursos/cot361_esterqueiralD-6sTAsWDBup.pdf. Acessado em 07/05/2016.

KUNZ, A.; HIGARASHI, M.M.; OLIVEIRA, P.A. Tecnologias de manejo e tratamento de dejetos de suínos estudadas no Brasil. Cadernos de Ciências \& Tecnologia, Brasília, v.22, n. 3, p. 651- 665, 2005.

KUNZ, A. Impactos sobre a disposição inadequada de dejetos de animais sobre a qualidade de águas superficiais e subterrâneas. Concórdia-SC: Embrapa Suínos e Aves, 2016. Disponível em: file://C:/Users/ana/Downloads/downloads-artigos-impactos-sobre-a-disposicao-airton-kunz.pdf. Acessado em 16/05/2016.

LASLOWSKI, M.A. Avaliação ambiental e econômica do biogásobtido através da biodigestão anaeróbia dos dejetos da suinocultura. 2004. 51 f. Monografia (Graduação em Engenharia Ambiental) - Centro de Ciências Exatas e Tecnológicas, PUCPR, Curitiba.

LAZARETTI, R.M.J.; SANTOS, J.M.G.; ANDREAZZI, M.A. Destinação dos resíduos da suinocultura em granjas das regiões sudoeste, norte e noroeste do Estado do Paraná. In: VIII EPCC - Encontro Internacional de Produção Cientifica, Maringá/PR: CESUMAR, 2013. Disponível em: http://www .cesumar.br/prppge/pesquisa/epcc2013/oit_mostra/Rhubia_Maria_Jorge_Lazaretti.pdf. Acessado em 14/05/2016. 
MEDRI, W.; COSTA, R.H.R.; PERDOMO, C.C. Estudo econômico e avaliação preliminar de sistema de tratamento: Lagoas Anaeróbia e Facultativa para dejetos suínos. In: Congresso Interamericano de Ingeniería Sanitaria y Ambiental, 25; Mexico, D.F., p. 1-8, 1996. Disponível em: http://www.bvsde.paho.org/bvsaidis/aresidua/mexico/01448p04.pdf. Acessado em 09/06/2016. MIYAZAWA, M.; BARBOSA, G.M.C.; PARRA, M.S. Lixiviação de nitrogênio no solo pela aplicação de dejeto de suíno. In: I Simpósio Internacional sobre Gerenciamento de Resíduos de Animais uso dos Resíduos da produção animal como Fertilizante. Florianópolis- SC, 2009.

OLIVEIRA, P.A.V. Tecnologias para o manejo de resíduos na produção de suínos. Projeto de controle da degradação ambiental decorrente da suinocultura em Santa Catarina, Manual de Boas Práticas, 1a Ed., Concórdia-SC: Embrapa Suínos e Aves/PNMAll, 2014. Disponível em: http://www.cnpsa.embrapa.br/sgc/sgc_publicacoes/publicacao_n3r85f3h.pdf. Acessado em 09/06/2016.

OLIVEIRA, P.A.V. Novas tecnologias são indicadas para tratamento de dejetos e uso racional de água e ração. Concórdia-SC: SNA Sociedade Nacional de Agricultura, Embrapa Suíno e Aves/Sebrae/Sistema OCB, 2016. Disponível em: http://sna.agr.br/novas-tecnologias-saoindicadas-para-tratamento-de-dejetos-e-uso-racional-de-agua-e-racao/. Acessado em 10/06/2016.

OLIVER, A.P.M. Manual de treinamento em biodigestão. Instituto de estúdios Hambre, 2008. Disponível em: http://www.ieham.org/html/docs/Manual_Biodigestao.pdf: Acessado em 10/11/2016.

PAIVA, D.P.; BLEY Jr, C.; PHILIPPI Jr., C. Compostagem de suínos mortos e restos de parição. Concórdia/SC: Embrapa Suínos e Aves, MAPA, 2001. Disponível em: https://www.infoteca.cnptia.embrapa.br/bitstream/doc/443229/1/CUsersPiazzonDocuments1564 2.pdf. Acessado em 11/06/2016.

PAIVA, D. P. Compostagem: destino correto para animais mortos e restos de parição. Embrapa Suíno e Aves, Concórdia- SC, 2016. Disponível em <https://www.agencia.cnptia.embrapa.br/Repositorio/compostagem_destino_correto_para_anim ais_mortos_e_restos_de_paricao_000fyr7aw9502wx5ok0pvo4k37obz7nl.pdf> Acessado em $11 / 06 / 2016$.

PERDOMO, C.C.; COSTA, R.R.H.; MEDRI, W.; MIRANDA, C.R. Dimensionamento de sistema de tratamento (Decantador de lagoas) e utilização de dejetos suínos. Comunicado Técnico, p. 1-5, CT 234, Embrapa Suínos e Aves, 1999. Disponível em: https://www.infoteca.cnptia.embrapa.br/bitstream/doc/436820/1/CUsersPiazzonDocuments234. pdf. Acessado em 07/06/2016.

PERDOMO, C. C. Uso racional da água no manejo de dejetos de suínos.In: I Seminário Mineiro sobre Manejo e Utilização de Dejetos de Suínos, Ponte Nova, MG, EPAMIG/EMATER/UFV/ASSUPAV, 2001.

PERDOMO, C.C.; LIMA, G.J.M.M.; NONES, K. Produção de suínos e meio ambiente. In: 9 Seminário Nacional de Desenvolvimento da Suinocultura, Gramado, RS, 2001. Disponível em: https://docsagencia.cnptia.embrapa.br/suino/anais/anais0104_perdomo.pdf. Acessado em $25 / 05 / 2016$. 
PINTO, L.P.; CABRAL, A.C.; SCHNEIDER, L.T.; FRIGO, K.D.A.; FRIGO, J.P.; FRIGO, E.P. Levantamento de dados sobre os dejetos suínos e suas características. Revista Brasileira de Energias Renováveis, v. 3, p. 179-187, 2014. DOI: http://dx.doi.org/10.5380/rber.v3i3.38467.

RANZI, T.J.D.; ANDRADE, M.A.N. Estudo de viabilidade de transformação de esterqueiras e bioesterqueiras para dejetos de suínos em biodigestores rurais visando o aproveitamento do biofertilizante e do biogás. In: Encontro de Energia no Meio Rural, 5, 2004. Proceedings online... Disponível

em: http://www.proceedings.scielo.br/scielo.php?pid=MSC0000000022004000100058\&script=sci_artt ext. Acessado em 06/06/2016.

RIZZONI, L.B.; TOBIAS, A.C.T.; DEL BIANCHI, M.; GARCIA, J.A.D. Biodigestão anaeróbia no tratamento de dejetos de suínos. Revista cientifica eletrônica de medicina veterinária, no 18, ano IX, $2012 . \quad$ Disponível em: http://faef.revista.inf.br/imagens_arquivos/arquivos_destaque/W34ebZOEZuzvEvG_2013-6-2818-12-37.pdf. Acessado em 07/06/2012.

SALES FILHO, I.O. Avaliação da toxicidade e remoção de matéria orgânica de efluente de biodigestor de resíduos sólidos orgânicos e tratado em wetlands. 2014. 63 f. Dissertação (Mestrado em Engenharia Civil e Ambiental) - Centro Acadêmico do Agreste, Universidade Federal de Pernambuco, Caruaru/PE.

SANTOS, E.L.B.; NARDI JUNIOR, G. Produção de biogás a partir de dejetos de origem animal. Tekhne e Logos, v.4, n.2, 2013.

SANTOS, A. C. Principais doenças que acometem os suínos. Centro de Produção Técnica, ViçosaMG, 2016. Disponível em:http://www.cpt.com.br/cursos-criacaodesuinos/artigos/principaisdoencas-que-acometem-os-suinos. Acessado em 30/05/2016.

SCHERER, E.E.; BALDISSERA, I.T.; NESI, C.N. Propriedades químicas de um Latossolo Vermelho sob plantio direto e adubação com esterco de suínos. Revista Brasileira de Ciência do Solo, v.31, p.123-131, 2007. https://doi.org/10.1590/S0100-06832007000100013

SCHERER, E.E.; NESI, C.N.; MASSOTTI, Z. Atributos químicos do solo influenciados por sucessivas aplicações de dejetos suínos em áreas agrícolas de Santa Catarina. Revista Brasileira de Ciência do Solo, v.34, n. 4, p.1375-1383, 2010. https://doi.org/10.1590/S0100-06832010000400034

SEGANFREDO, M. A. Os dejetos de suínos são um fertilizante ou um poluente do solo? Cadernos de Ciência \& Tecnologia, v.16, n.3, p.129-141, 1999.

SEGANFREDO, M. A.; SOARES, I.J.; KLEIN, C.S. Potencial fertilizante e poluente dos dejetos de suínos no contexto das pequenas propriedades do Oeste de SC. Comunicado Técnico, n.342, Embrapa Suíno e Aves/MAPA, Concórdia-SC, 2003. Disponível em: http://ainfo.cnptia.embrapa.br/digital/bitstream/CNPSA/15665/1/cot342.pdf. Acessado em 19/05/2016.

SERPA FILHO, R.; SEHNEM, S.; CERICATO, A.; SANTOS Jr., S.; FISCHER, A. Compostagem de dejetos de suínos. Revista em Agronegócios e Meio Ambiente, v.6, n.1, p. 47-78, 2013. 
SILVA, F.L. Lagoas de estabilização de dejetos suínos: Avaliação da eficiência de um sistema empregando parâmetros físico-químicos e biológicos. Dissertação (Mestrado), Universidade Federal de Minas Gerais (UFMG), Escola de Veterinária, Belo Horizonte-MG, 2003.

SILVA, N.P.; FRANCISCO, A.C. Geração de energia elétrica a partir de dejetos suínos: Um estudo de caso em uma propriedade rural na região oeste do estado do Paraná. Nucleus, v.7, n.2, 2010. SILVA, I.J.; RODRIGUES, L.S. Destinação de cadáveres e outros resíduos biológicos. ABCS- Produção de suínos teoria e prática, Ed.1, Brasília, 2014.

SILVA, C.L.; BASSI, N.S.S; NASCIMENTO, D.E. Implantação de políticas públicas pelas instituições públicas de pesquisa: um estudo sobre pesquisa e tecnologias da Embrapa Suínos e Aves para mitigação do impacto ambiental da suinocultura no oeste catarinense, Espacios, v.32, n.4, p.10, 2011. Disponível em: http://www.revistaespacios.com/a11v32n04/11320442.html. Acessado em 07/06/2016.

SILVA, C. M.; FRANÇA, M.T.; OYAMADA, G.C. Características da suinocultura e os dejetos causados ao meio ambiente. Connection line, n.12, p.44-59, 2015. DOI: http://dx.doi.org/10.18312\%2F1980-7341.n12.2015.199

SILVA FILHO, P.A. Diagnóstico operacional de lagoas de estabilização. 2007. 169 f. Dissertação (Mestrado em Engenharia Sanitária) - Centro de Tecnologia, Universidade Federal do Rio Grande do Norte, Natal/RN.

SOUZA, C. F.; CARVALHO, C.C.S.; CAMPOS, J.A.; MATOS, A.T.; FERREIRA, W.P.M. Caracterização de dejetos de suínos em fase de terminação. Revista Ceres, v.56, n.2, p.128-133, 2009.

TARRENTO, G. E.; MARTINES, J. C. Análise da implantação de biodigestores em pequenas propriedade rurais, dentro do contexto da produção limpa. SIMPEPE, 13, Bauru- SP, 2006.

VIVAN, M.; KUNZ, A.; STOLBERG, J.; PERDOMO, C.C.; TECHIO, V.H. Eficiência da interação biodigestor e lagoas de estabilização na remoção de poluentes em dejetos de suínos. Revista Brasileira de Engenharia Agrícola e Ambiental, v.14, n.3, p.320-325, 2010. https://doi.org/10.1590/S1415-43662010000300013

ZORDAN, M.S.; SALÉH, B.B.; MENDONÇA, A. Eficiência na remoção de nutrientes em lagoas de estabilização da granja escola FESURV. Global Science and Technology, v. 01, n. 01, p. 51-62, 2008. 